\title{
Adaptation to pelleted feed in pikeperch fingerlings: learning from the trainer fish over gradual adaptation from natural food
}

\author{
Pavel Lepič, Milos Buřič*, Jiří Hajíček and Pavel Kozák \\ University of South Bohemia in Ceske Budejovice, Faculty of Fisheries and Protection of Waters, South Bohemian Research \\ Center of Aquaculture and Biodiversity of Hydrocenoses, Zátisí 728/II, 38925 Vodnany, Czech Republic
}

Received 6 March 2017 / Accepted 27 February 2017

\begin{abstract}
Pikeperch (Sander lucioperca) is commercially important as well as a valued culinary fish with potential for intensive culture. One of the basic problems in pikeperch culture in recirculating aquaculture systems is adapting early life stages to pelleted feed (PF). Our work compares four different ways of adapting 6-week-old pikeperch fingerlings (standard length, SL $=29.30 \pm 2.14 \mathrm{~mm}$; weight, $W=0.38 \pm 0.08 \mathrm{~g}$ ) to feeding on a commercial diet. The methods are designated, $\mathrm{A}-$ use of trainer fish (Vimba vimba; $\mathrm{SL}=36.88 \pm 3.28 \mathrm{~mm} ; W=0.77 \pm 0.26 \mathrm{~g}$ ) and direct application of $\mathrm{PF} ; \mathrm{B}-$ use of trainer fish and gradual addition of PF with natural food (natural feed (NF), chironomid larvae); $\mathrm{C}$ - direct application of PF only; D - gradual addition of PF with NF. The growth trial experiment (including adaptation to PF) lasted 14 days by which time all experimental groups were accepting PF. Pikeperch fingerlings in group A grew significantly faster and PF was more readily accepted compared to other groups $(\mathrm{SL}=46.11 \pm 4.09 \mathrm{~mm}$; $W=1.44 \pm 0.38 \mathrm{~g}$; specific growth rate $=9.48 \pm 0.83 \%$ day $^{-1}$ ). Other characteristics observed (total weight increment, feed conversion ratio) also support the use of trainer fish and direct application of PF for pikeperch in their adaptation to intensive culture. It is also an illustration of applicable use of learning potential in fish which can be usable for other fish species.
\end{abstract}

Keywords: Aquaculture / Pikeperch / Feed / Social learning

\section{Introduction}

The growing human population and the increasing demand for quality and healthy food together with problems related to over-harvesting of oceanic fisheries are the most important factors which make aquaculture one of the most progressive food-producing sectors today (Food and Agriculture Organization of United Nations, 2014). Recent developments in aquaculture are exemplified by the use of intensive recirculating aquaculture systems (RASs) which provide solutions to limitations of water resources and management of effluents i.e. to provide economic and environmental sustainability (Martins et al., 2010; National Intelligence Council, 2012; Buřič et al., 2015). On the other hand, considerable effort is spent on implementation of intensive culture for new species in RAS. Pikeperch (Sander lucioperca) is commercially important, attractive and valued for its culinary attributes and is increasingly being reared in RAS in Europe, with potential for further use in intensive aquaculture (Philipsen and van der Kraak, 2008; Frisk et al., 2012; Hermelink et al., 2013). This is

\footnotetext{
* Corresponding author: buric@frov.jcu.cz
}

valid also for the related North American species, walleye (Sander vitreus), which tends to be a more important aquaculture species in Canada and USA (Summerfelt, 2004; Zarnoch et al., 2010). Reproduction, both artificial and semiartificial, is well mastered and when combined with early pond culture of larvae and fingerlings it is possible to obtain an adequate supply of fish for adaptation to pelleted feed (PF) (Bódis et al., 2007; Policar et al., 2013a). There have been other considerable advances in intensive perciform fish culture and research, but a basic problem is to adapt the early life stages to PF so as to take full advantage of their growth capacity (Summerfelt, 2004; Policar et al., 2013a).

There have been different approaches to adapting a predatory fish such as pikeperch to commercial PF. Various species differ in the time of adaptation (age of adapted fish), method (density, feed type, use of natural feed (NF) or cultured live feed etc.) and their combinations (Summerfelt, 2004; Molnar et al., 2004; Ostaszewska et al., 2005; Hamza et al., 2007; Policar et al., 2013b). In walleye, clay turbidity is considered essential for enhancing intensive walleye culture in tanks, as it provides visual contrast for the prey and leads to reduction of cannibalism and clinging behavior in larval stages (Clayton et al., 2009). Taking growth capacity into account in 
relation to the technical difficulties, the most probable optimization would be to adapt 6-week-old pond raised fingerlings to a formulated pelleted diet and then habituate them to it (Steffens et al., 1996; Summerfelt, 2004; Bódis et al., 2007; Policar et al., 2013a). Six-week-old juveniles are 30$50 \mathrm{~mm}$ and initiate predatory feeding (including cannibalism) on fish (Antalfi, 1979; Steffens et al., 1996), which is the optimal stage for training to a nutritious PF. Usually PF is gradually and increasingly given so as to replace NF. Good results have been achieved using chironomid larvae initially with gradual addition of PF (Bódis et al., 2007; Policar et al., 2013b). Recently, "trainer fish" such as previously trained pikeperch and perch were used to facilitate the adaptation or training to PF (Horváth et al., 2013) but this approach has been demonstrated only for yearlings and was unsuccessful.

However, the use of trainer fish seemed a promising avenue for future research and practice especially for younger fish, as the 6-weeks-old pikeperch described above. There is a possibility to gain from the usual behavioral patterns of earlier developmental stages of fish such as shoaling behavior (Hager and Helfman, 1991; Pitcher, 2001) which can increase protection against predators and optimal food gathering (Pitcher, 1986, 2001). When fish form a compact shoal, then, apart from the above mentioned benefits, they can learn from each other in space and time, e.g. in the case of feeding behavioral patterns (Lachlan et al., 1998; Chapman et al., 2008). Similar patterns, called social learning, are known from different animal taxa and in a not negligible extent also in teleost fish species (Laland and Williams, 1997; Brown and Laland, 2003). Social learning was successfully tested in hatchery reared fish for improving their post-release survival (Brown and Laland, 2001). Our work could show how to practically apply this behavioral concept in commercial aquaculture.

We designed an experiment for 6-week-old pond-raised pikeperch fingerlings which compared the gradual transition from NF to PF, direct application of PF, and both approaches, using a cyprinid "trainer fish" in RAS. The main goal of the experimental work was to explore the potential benefits, advantages or disadvantages, so as to find the most appropriate method for pikeperch adaptation to PF. The results should outline how to minimize inputs and maximize outputs in the production of pikeperch fingerlings intended for further intensive culture in RAS.

\section{Materials and methods}

\subsection{Experimental animals and conditions}

Fish were used from separate cultures of two species, pikeperch and vimba bream (Vimba vimba). Pikeperch were raised by a semi-artificial breeding approach using hormonal stimulation and semi-natural spawning on provided transferable substrates. Prior to hatching, nests with eyed eggs were transferred to prepared ponds in May 2015 (Policar et al., 2008; Krist'an et al., 2013; Policar et al., 2013b). After 6 weeks of pond rearing, fingerlings (standard length, $\mathrm{SL}=29.30 \pm$ $2.14 \mathrm{~mm}$; weight, $W=0.38 \pm 0.08 \mathrm{~g}$ ) were harvested, acclimated to experimental conditions and stocked in tanks. The trainer fish vimba bream, a cyprinid inhabiting lower or middle reaches of warm rivers in Europe and western Asia (Kottelat and Freyhof, 2007), was chosen due to its availability in time
Table 1. Experimental conditions in the recirculating aquaculture system during experiment. Data are presented as mean \pm standard deviation.

\begin{tabular}{lc}
\hline Parameter & Mean \pm standard deviation \\
\hline Water temperature $\left({ }^{\circ} \mathrm{C}\right)$ & $21.39 \pm 1.07$ \\
Dissolved oxygen $\left(\mathrm{mg} \mathrm{L}^{-1}\right)$ & $8.48 \pm 0.85$ \\
$\mathrm{pH}$ & $6.99 \pm 0.33$ \\
Ammonia, $\mathrm{NH}_{4}^{+}\left(\mathrm{mg} \mathrm{L}^{-1}\right)$ & $0.22 \pm 0.06$ \\
Nitrite, $\mathrm{NO}_{2}^{-}\left(\mathrm{mg} \mathrm{L}^{-1}\right)$ & $0.22 \pm 0.12$ \\
\hline
\end{tabular}

and good experiences with feeding with PF (Hamackova et al., 2009). One-year-old vimba bream were harvested from ponds in April 2015 and stocked in a flow-through system for training to $\mathrm{PF}$. After the PF acceptance, vimba bream $(\mathrm{SL}=36.88 \pm 3.28 \mathrm{~mm} ; W=0.77 \pm 0.26 \mathrm{~g})$ were moved for acclimation to experimental conditions before stocking in the experimental set-up.

Four types of experimental conditions were used: A pikeperch with trainer fish and direct application of PF, B pikeperch with trainer fish and gradual addition of $\mathrm{PF}$ to natural food (NF, chironomid larvae), C - pikeperch without trainer fish and direct application of $\mathrm{PF}$, and $\mathrm{D}$ - pikeperch without trainer fish and gradual addition of PF to NF. Each group consisted of 3600 pikeperch fingerlings and, in groups A and C, also of 720 vimba bream juvenile trainer fish. The initial biomass was $2.39 \mathrm{~kg} \mathrm{~m}^{3-1}$ with trainer fish and $1.69 \mathrm{~kg} \mathrm{~m}^{3-1}$ without them. Each experimental group was stocked in triplicate.

The experimental work, including fingerling rearing and acclimation, was carried out in the RAS of the Experimental Fish Culture Facility of Research Institute of Fish Culture and Hydrobiology. Oxygen saturation levels and water temperatures (oximeter Oxi 3205 with CellOx ${ }^{\circledR}$ 325, WTW Gmbh, Weilheim, Germany) were monitored twice daily and $\mathrm{pH}(\mathrm{pH}$ meter pH 330i with SenTix 41, WTW Gmbh, Weilheim, Germany), ammonia $\left(\mathrm{NH}_{4}{ }^{+}\right)$and nitrite $\left(\mathrm{NO}_{2}{ }^{-}\right)$(by colorometric analysis) content was monitored daily (Table 1). Experimental tanks were $1 \mathrm{~m} \times 1 \mathrm{~m} \times 0.8 \mathrm{~m}\left(0.8 \mathrm{~m}^{3}\right)$; they were cleaned daily. Light regime was set to $16 \mathrm{~h}$ light and $8 \mathrm{~h}$ dark.

Fish were fed to satiation (feeding was stopped when fish did not react to feed) hourly during the light period. That means that feed was applied in total 15 times per day - feeding started $1 \mathrm{~h}$ after the beginning of light period and the last feeding was conducted $1 \mathrm{~h}$ before its end. Visual observations of fish behavior were made during each feed application. Uneaten feed was removed and the feed ration for the next hour was weighed. Due to the feeding procedure used the amount of uneaten feed was negligible and was not included in the calculations, where only the amount of feed provided is used. This complicated system of feed dosage was necessary to maintain the pre-determined ratio between NF and PF, when both diet components were applied. The daily feed rations of $\mathrm{PF}$ and NF for all experimental groups are presented in Table 2. Frozen chironomid larvae (NF) and a commercial PF (Inicio Plus, Biomar A/S, Denmark) were used. The training or adaptation period lasted 14 days, by which time all experimental groups were well trained to the PF, and thereafter only PF was given. 
Table 2. Daily feed rations in grams (wet weight was used for natural feed) in four experimental set-ups used for pikeperch adaptation to commercial pelleted feed: pikeperch with trainer fish and direct application of pelleted feed (A); pikeperch with trainer fish and gradual addition of pelleted feed to natural food (B); pikeperch without trainer fish and direct application of pelleted feed (C); pikeperch without trainer fish and gradual addition of pelleted feed to natural feed (D). The proportion of pelleted feed (\% of PF) in the total weight of applied feed is presented in groups where natural (NF) and pelleted feed (PF) was used.

\begin{tabular}{|c|c|c|c|c|c|c|c|c|}
\hline \multirow[t]{2}{*}{ Day } & \multicolumn{4}{|c|}{ Pikeperch with trainer fish } & \multicolumn{4}{|c|}{ Pikeperch without trainer fish } \\
\hline & $\begin{array}{l}\text { A } \\
\text { PF }\end{array}$ & NF & PF & $\%$ of PF & $\begin{array}{l}\mathrm{C} \\
\mathrm{PF}\end{array}$ & NF & PF & $\%$ of $\mathrm{PF}$ \\
\hline 1 & 90 & 630 & 0 & 0 & 45 & 500 & 0 & 0 \\
\hline 2 & 135 & 595 & 0 & 0 & 65 & 485 & 0 & 0 \\
\hline 3 & 170 & 780 & 0 & 0 & 100 & 520 & 0 & 0 \\
\hline 6 & 190 & 407 & 275 & 40 & 120 & 407 & 275 & 40 \\
\hline 7 & 165 & 261 & 261 & 50 & 100 & 261 & 261 & 50 \\
\hline 8 & 195 & 163 & 243 & 60 & 130 & 163 & 243 & 60 \\
\hline 9 & 210 & 112 & 267 & 70 & 140 & 112 & 267 & 70 \\
\hline 10 & 190 & 81 & 325 & 80 & 125 & 81 & 325 & 80 \\
\hline 14 & 185 & 0 & 190 & 100 & 185 & 0 & 195 & 100 \\
\hline Total feed amount (g) & 2745 & 4371 & 2911 & $X$ & 1810 & 3871 & 2781 & $X$ \\
\hline
\end{tabular}

\subsection{Data acquisition}

The amount of feed and mortality were recorded daily. In both fish species, pikeperch and vimba bream, SL was measured to an accuracy of $1 \mathrm{~mm}$ and weight to the nearest $0.01 \mathrm{~g}$ with an electronic balance (Kern \& Sohn GmbH, Balingen, Germany), initially and at the end of the experiment. A random sample of fifty specimens per replicate was measured and weighed for each species. Calculations included:

Total weight increment (TWI, g):

$$
\mathrm{TWI}=\mathrm{TBf}-\mathrm{TBi},
$$

where $\mathrm{TBf}=$ total final biomass $(\mathrm{g})$ and $\mathrm{TBi}=$ total initial biomass $(\mathrm{g})$ in the experimental stock.

Feed Conversion Ratio (FCR) using the following formula:

$$
\mathrm{FCR}=\mathrm{Wf} / \mathrm{TWI}
$$

where $\mathrm{Wf}=$ amount of $\mathrm{PF}$ applied $(\mathrm{g})$ and TWI $=$ obtained TWI (g) in the experimental stock. In experimental groups B and D the FCR calculation is based on PF only, without the contribution of NF.

Specific growth rate (SGR, \% per day)

$$
\mathrm{SGR}=(\ln (\mathrm{Wt})-\ln (\mathrm{Wi})) \times 100 / T,
$$

where $\mathrm{Wt}=$ weight at time $t(\mathrm{~g}), \mathrm{Wi}=$ initial weight $(\mathrm{g})$ and $T=$ time (days).

\subsection{Data analysis}

Data were analyzed using Statistica 12.0 (StatSoft, Inc.). Results were first examined for normal distribution (Kolmogorov-Smirnov test). Non-parametric Kruskal-Wallis test with multiple comparisons post hoc test was used to analyze the mortality, FCR, SGR and TWI; nested analysis of variance (ANOVA) was used for to analyze SL and weight of pikeperch and vimba bream in different experimental groups at the end of experiments (replicate tanks as a random factor, experimental group as a fixed factor) with Tukey's post-hoc test, $t$-test was used for comparison of vimba bream standard length (SL) and weight, and Mann-Whitney test was used for comparison of vimba bream TWI and SGR at the end of experiment. The null hypothesis was rejected at $\alpha=0.05$. Data are presented as means \pm standard deviation (STD).

\section{Results}

Mortality did not differ among experimental groups (Kruskal-Wallis test, $H=3.10 ; \mathrm{df}=3 ; P=0.38$ ) and ranged among $7.3-15.9 \%, 9.4-13.5 \%, 9.8-14.7 \%$, and $5.5-11.0 \%$ in experimental groups A, B, C, and D, respectively (Table 3 ). Final size and weight of pikeperch fingerlings was significantly higher in group A (ANOVA, $F=44.99 ; \mathrm{df}=3 ; P<0.05$ and $F=34.43 ; \mathrm{df}=3 ; P<0.05$, respectively). There were no detected significant differences between replicates within experimental groups regarding SL and $W$ (ANOVA, $F=1.99$; $\mathrm{df}=2 ; P=0.14$ and $F=0.03 ; \mathrm{df}=2 ; P=0.97)$. SGR was 
Table 3. Mortality, standard length (SL), weight $(W)$, total weight increment (TWI) reached at the end of the experiment and feed conversion ratio (FCR) obtained in all experimental groups of pikeperch fingerling: pikeperch with trainer fish and direct application of pelleted feed - PF (A); pikeperch with trainer fish and gradual addition of pelleted feed to natural food - PF + NF (B); pikeperch without trainer fish and direct application of pelleted feed $-\mathrm{PF}(\mathrm{C})$; pikeperch without trainer fish and gradual addition of pelleted feed to natural feed $-\mathrm{PF}+\mathrm{NF}(\mathrm{D})$. Data are presented as mean \pm standard deviation. Values in the same row with different superscripts differ significantly $(\alpha=0.05)$.

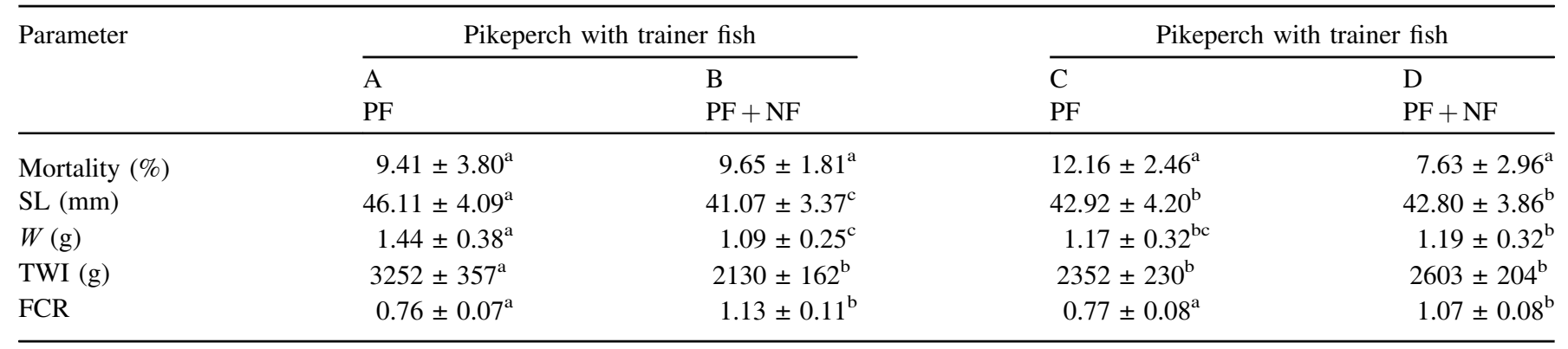

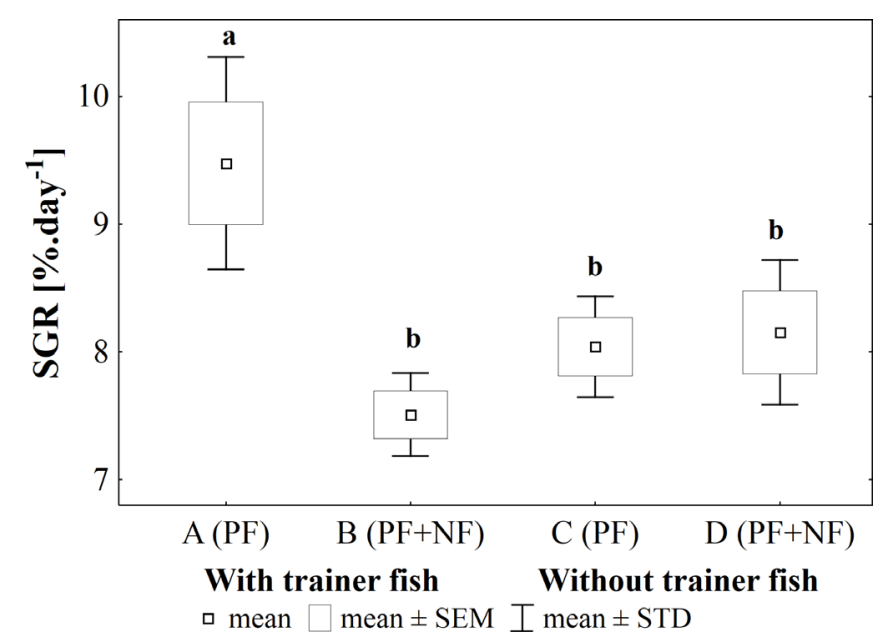

Fig. 1. Specific growth rate (SGR) achieved in pikeperch fingerlings in all experimental groups of pikeperch fingerling: pikeperch with trainer fish and direct application of pelleted feed - A (PF); pikeperch with trainer fish and gradual addition of pelleted feed to natural food $\mathrm{B}(\mathrm{PF}+\mathrm{NF})$; pikeperch without trainer fish and direct application of pelleted feed - $\mathrm{C}(\mathrm{PF})$; pikeperch without trainer fish and gradual addition of pelleted feed to natural feed $-\mathrm{D}(\mathrm{PF}+\mathrm{NF})$. Data are presented as mean, standard error of mean (SEM), and standard deviation (STD). Values with different superscripts differ significantly $(\alpha=0.05)$.

significantly poorer in group B (for detailed information see Table 3). The apparently higher SGR in group A was also significantly different (Kruskal-Wallis test, $H=8.91$; df $=3$; $P<0.05$ ) from other groups (Fig. 1).

TWI was obviously also significantly greater (KruskalWallis test, $H=8.64 ; \mathrm{df}=3 ; P<0.05$ ) in group A, but with no difference among the other three groups (Table 3). The FCR, calculated for PF only, was significantly higher (KruskalWallis test, $H=9.51 ; \mathrm{df}=3 ; P<0.05$ ) in groups where only $\mathrm{PF}$ was given (group A and C) with no difference between them, despite the overestimation of FCR in groups with application of NF (not included in calculations) (Table 3). Group C had very good FCR, but the amount of feed applied in accordance to fish foraging behavior was lower (Table 2).
Table 4. Standard length (SL), weight $(W)$, total weight increment attained (TWI) and specific growth rate (SGR) for vimba bream used as trainer fish at the end of the experiment in group A (pikeperch with trainer fish and direct application of pelleted feed - PF) and B (pikeperch with trainer fish and gradual addition of pelleted feed to natural food $-\mathrm{PF}+\mathrm{NF}$ ). Data are presented as mean \pm standard deviation. Values in the same row with different superscripts differ significantly $(\alpha=0.05)$.

\begin{tabular}{lcr}
\hline Parameter & \multicolumn{1}{l}{ A } & \multicolumn{1}{l}{$\mathrm{B}$} \\
& \multicolumn{1}{l}{ PF } & \multicolumn{1}{c}{ PF + NF } \\
\hline Mortality (\%) & $2.69 \pm 0.76^{\mathrm{a}}$ & $2.73 \pm 0.63^{\mathrm{a}}$ \\
SL $(\mathrm{mm})$ & $43.14 \pm 6.66^{\mathrm{a}}$ & $44.42 \pm 4.04^{\mathrm{a}}$ \\
$W(\mathrm{~g})$ & $1.32 \pm 0.41^{\mathrm{a}}$ & $1.46 \pm 0.45^{\mathrm{a}}$ \\
TWI $(\mathrm{g})$ & $371 \pm 31^{\mathrm{a}}$ & $470 \pm 116^{\mathrm{a}}$ \\
SGR $\left(\%\right.$ day $\left.^{-1}\right)$ & $3.85 \pm 0.24^{\mathrm{a}}$ & $4.60 \pm 0.74^{\mathrm{a}}$ \\
\hline
\end{tabular}

The growth of trainer fish was identical among groups SL and $W$ (ANOVA, $F_{1,90}=1.33 ; \mathrm{df}=1,90 ; P=0.25$ and $F=2.33 ; \mathrm{df}=1,90 ; P=0.13$ respectively), and SGR and TWI did not differ significantly (Mann-Whitney test, $Z=-1.31$; $P=0.19$ and $Z=-0.87 ; P=0.38$, respectively). There were no detected significant differences between replicates within experimental groups regarding SL and $W$ (ANOVA; $F=1.76$, df $=2, \quad 90 ; \quad P=0.18$ and $F=1.48 ; \quad$ df $=2, \quad 90 ; \quad P=0.23$ respectively) (Table 4$)$.

\section{Discussion}

In the present study we used 6-week-old pond raised fingerlings for the training-period of 14 days. We tested trainer fish to facilitate the efficiency of acceptance of PF, with and without gradual transition from NF. Trainer fish were selected following three basic criteria: larger size at the beginning of experiment (to avoid predation), fish well adapted to PF (to facilitate pikeperch acclimation to PF), and slower growth (to avoid increased competition with pikeperch). Following these criteria, we used 1-year-old pond cultured vimba bream which had been trained to PF. Other species can be used as trainers, depending on availability. A similar design was used 
by Horváth et al. (2013), but they were not successful, probably due to the use of yearling pikeperch which had been feeding as predators for at least one growing season, and probably also because of aggressive trainers (adapted pikeperch and perch, Perca fluviatilis) or unsuitable rearing conditions (small scale experimental aquaria). The other reason could be the individualistic behavioral patterns in such old specimens, which probably revoked the effect of social learning which can easily occur in a compact shoal of fish (Lachlan et al., 1998; Kelley et al., 2003).

We demonstrated the positive effect of trainer fish in the present study when PF was applied from the first day. Pikeperch fingerlings fed on PF were positively stimulated by the foraging activity of vimba bream. It is surprising how early pikeperch specimens adapted to the new situation, formed a compact shoal with vimba bream and fed similarly to them on the new food item. This behavioral imitation illustrates the capability of fish for social learning, as suggested also by Brown and Laland (2001), and its practical use in aquaculture. In the present study this ability led to direct acceptance of PF which resulted in better growth and therefore bigger size, better SGR, and higher TWI at the end of the experiment. Moreover, the direct application of PF did not affect survival in this group. On the other hand, combining trainer fish with gradual application of PF to NF was not beneficial. This is probably due to active feeding by pikeperch on chironomid larvae, while the PF was predominantly utilized by trainer fish. Generally, the learning effect from the trainer fish was therefore reduced by selection for a preferred food item. Prolongation of the test period affected the growth of pikeperch. Surprisingly, similar results were observed in both experimental groups without trainer fish, whether with or without application of NF. The only negative effect in the group receiving direct application of $\mathrm{PF}$ to pikeperch fingerlings was lower growth. That was partly compensated by better FCR which did not differ from group A (trainer and direct application of PF). Notwithstanding, group A fish fed more actively (subjective personal observation), which led to significantly better growth parameters.

Pikeperch fingerlings equaled the higher weight of vimba bream at the end of the experiment and there was no predation on trainer fish. At that time the trainer fish could be removed and the species reared separately. Trainer fish can therefore be used in production of this species, or could potentially be used as natural food for brood stock. We can therefore harvest large pikeperch fingerlings adapted to dry PF together with another "by-product", vimba bream, e.g. for restocking. Probably different non-aggressive PF-trained and valuable cyprinid species could also be used, such as tench (Tinca tinca) (Pantazis and Hatzinikolaou, 2011) or even commercially unimportant common species like roach (Rutilus rutilus) or rudd (Scardinius erythrophtalmus).

The present approach may provide a new way to obtain well-adapted pikeperch fingerlings for intensive culture and overcome the present limiting factor of supply for pikeperch aquaculture in RAS using dry PF. The use of trainer fish could also be applicable to different fish species to streamline their fingerling production. Finally, the described approach demonstrates the applicability of the concept of social learning in fish. The simplicity with which the trained fish accepted the behavior of trainer fish extends the possibility of wide applicability of the trainer-fish approach in general. Further experimentation is needed to evaluate how broadly the "trainer approach" could be applied to different species.

Acknowledgements. The work was supported by the Ministry of Education, Youth and Sports of the Czech Republic projects "CENAKVA" (No. CZ.1.05/2.1.00/01.0024) and "CENAKVA II" (No. LO1205 under the NPU I programme), and by the Ministry of Agriculture of the Czech Republic (project No. NAZV QJ1510119). We also deeply appreciate the assistance of Prof. William L. Shelton and Prof. Julian Reynolds for the language editing of this manuscript.

\section{References}

Antalfi A. 1979. Propagation and rearing of pikeperch in pond culture. EIFAC Technical Paper 35.

Bódis M, Kucska B, Bercsényi M. 2007. The effect of different diets on the growth and mortality of juvenile pikeperch (Sander lucioperca) in the transition from live food to formulated feed. Aquac Int 15: 83-90.

Brown C, Laland KN. 2001. Social learning and life skills training for hatchery reared fish. J Fish Biol 59: 471-493.

Brown C, Laland KN. 2003. Social learning in fishes: a review. Fish Fish 4: 280-288.

Buřič M, Bláhovec J, Kouřil J. 2015. Back to the roots: the integration of a constructed wetland to the recirculating hatchery - case study. PLoS One 10 (4): e0123577. DOI: 10.13701/journal. pone.0123577.

Chapman BB, Ward AJ, Krause J. 2008. Schooling and learning: early social environment predicts social learning ability in the guppy, Poecilia reticulata. Anim Behav 76: 923-929.

Clayton RD, Morris JE, Summerfelt RC. 2009. Effect of turbidity duration on culture of walleye larvae. N Am J Aquac 71 (2): 174177.

Food and Agriculture Organization of United Nations. 2014. The state of world fisheries and aquaculture, opportunities and challenges. Rome: FAO.

Frisk M, Skov PV, Steffensen JF. 2012. Thermal optimum for pikeperch (Sander lucioperca) and the use of ventilation frequency as a predictor of metabolic rate. Aquaculture 324: 151-157.

Hager MC, Helfman GS. 1991. Safety in numbers: shoal size choice by minnows under predatory threat. Behav Ecol Sociobiol 29: 271-276.

Hamackova J, Prokes M, Kozak P, et al. 2009. Growth and development of vimba bream (Vimba vimba) larvae in relation to feeding duration with live and/or dry starter feed. Aquaculture 287: 158-162.

Hamza N, Mhetli M, Kestemont P. 2007. Effects of weaning age and diets on ontogeny of digestive activities and structures of pikeperch (Sander lucioperca) larvae. Fish Physiol Biochem 33: 121-133.

Hermelink B, Wuertz S, Rennert B, Kloas W, Schulz C. 2013. Temperature control of pikeperch (Sander lucioperca) maturation in recirculating aquaculture systems-induction of puberty and course of gametogenesis. Aquaculture 400: 36-45.

Horváth Z, Németh S, Beliczky G, Felföldi Z, Bercsényi M. 2013. Comparison of efficiencies of using trainer fish and shape or taste modified feed for enhancing direct weaning of pikeperch (Sander lucioperca L.) yearlings on dry feed. Croat J Fish 71: 151-158. 
Kelley JL, Evans JP, Ramnarine IW, Magurran AE. 2003. Back to school: can antipredator behaviour in guppies be enhanced through social learning? Anim Behav 65: 655-662.

Kottelat M, Freyhof J. 2007. Handbook of European freshwater fishes. Kottelat, Cornol, Switzerland and Freyhof, Berlin, Germany, 646 p.

Krist'an J, Alavi SMH, Stejskal V, Policar T. 2013. Hormonal induction of ovulation in pikeperch (Sander lucioperca L.) using human chorionic gonadotropin (hCG) and mammalian GnRH analogue. Aquac Int 21: 811-818.

Lachlan RF, Crooks L, Laland KN. 1998. Who follows whom? Shoaling preferences and social learning of foraging information in guppies. Anim Behav 56: 181-190.

Laland KN, Williams K. 1997. Shoaling generates social learning of foraging information in guppies. Anim Behav 53: 1161-1169.

Martins CIM, Eding EH, Verdegem MCJ, et al. 2010. New developments in recirculating aquaculture systems in Europe: a perspective on environmental sustainability. Aquac Eng 43: 83-93.

Molnar T, Hancz C, Bodis M, Muller T, Bercsemyi M, Horn P. 2004. The effect of initial stocking density on growth and survival of pike-perch fingerlings reared under intensive conditions. Aquac Int 12: 181-189.

National Intelligence Council. 2012. Global trends 2030: alternative worlds. Washington: Office of the Director of National Intelligence.

Ostaszewska T, Dabrowski K, Czuminska K, Olech W, Olejniczak M. 2005. Rearing of pike-perch larvae using formulated diets - first success with starter feeds. Aquac Res 36: 1167-1176.

Pantazis PA, Hatzinikolaou A. 2011. The effect of ration level on the growth and survival of sub-adult tench (Tinca tinca L 1758) in a recirculating water system. Mar Freshw Behav Physiol 44: $125-130$.
Philipsen E, van der Kraak G. 2008. Excellence fish: production of pikeperch in recirculating system. In: Fontaine P, Kestemont P, Teletchea F, Wang N, eds. Percid fish culture, from research to production. Namur, Belgium: Presses Universitaires de Namur, $67 \mathrm{p}$.

Pitcher TJ. 1986. Functions of shoaling behaviour in teleosts. In: Pitcher TJ, ed. The behaviour of teleost fishes. US: Springer, pp. 294-337.

Pitcher TJ. 2001. Fish schooling: implications for patter in the oceans and impacts on human fisheries. In: Steele JH, Turekian KK, Thorpe SA, eds. Encyclopedia of ocean sciences. UK: Academic Press, pp. 975-987.

Policar T, Blecha M, Kristan J, Stejskal V, Bláha M. 2013a. Combination of intensive (RAS) and extensive (pond) aquaculture for juvenile production in pikeperch (Sander lucioperca). In: Poleksic V, ed. VI International Conference "Water \& Fish", Belgrade-Zemun, Serbia, pp. 88-91.

Policar T, Kouril J, Stejskal V, Hamackova J. 2008. Induced ovulation of perch (Perca fluviatilis L.) by preparations containing GnRHa with and without metoclopramide. Cybium 32: 308-308.

Policar T, Stejskal V, Kristan J, Podhorec P, Svinger V, Blaha M. 2013b. The effect of fish size and stocking density on the weaning success of pond-cultured pikeperch Sander lucioperca L. juveniles. Aquac Int 21: 869-882.

Steffens W, Geldhauser F, Gerstner P, Hilge V. 1996. German experiences in the propagation and rearing of fingerling pikperch (Stizostedion lucioperca). Ann Zool Fenn 33: 627-634.

Summerfelt RC. 2004. Intensive culture of walleye in the United States. Aquaculture Canada 2004, Special Publication Aquaculture Association of Canada 11, pp. 173-182.

Zarnoch CB, Schreibman MP, Colesante RT, Timmons MB. 2010. Growth performance of Walleye, Sander vitreus, in recirculating aquaculture systems. J Appl Aquacult 22 (4): 285-296.

Cite this article as: Lepič P, Buřič M, Hajíček J, Kozák P. 2017. Adaptation to pelleted feed in pikeperch fingerlings: learning from the trainer fish over gradual adaptation from natural food. Aquat. Living Resour. 30: 8 